\title{
Assessing internet-based information used to aid patient decision- making about surgery for perianal Crohn's fistula
}

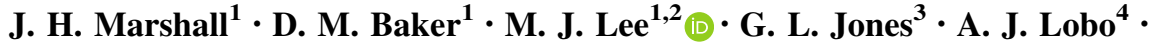 \\ S. R. Brown ${ }^{2}$
}

Received: 17 May 2017/ Accepted: 18 May 2017/Published online: 22 June 2017

(c) The Author(s) 2017. This article is an open access publication

\begin{abstract}
Background Decision-making in perianal Crohn's fistula (pCD) is preference sensitive. Patients use the internet to access healthcare information. The aim of this study was to assess the online information and patient decision aids relating to surgery for $\mathrm{pCD}$.

Methods A search of Google ${ }^{\mathrm{TM}}$ and the Decision Aids Library Inventory (DALI) was performed using a predefined search strategy. Patient-focussed sources providing information about pCD surgery were included in the analysis. Written health information was assessed using the
\end{abstract}

Conference presentation:East Midlands Surgical Society Summer Meeting, Leicester, 2017.

J. H. Marshall

jmarshall1@sheffield.ac.uk

D. M. Baker

dmbaker1@sheffield.ac.uk

M. J. Lee

m.j.lee@sheffield.ac.uk

G. L. Jones

G.L.Jones@leedsbeckett.ac.uk

A. J. Lobo

alan.lobo@sth.nhs.uk

S. R. Brown

Steven.Brown@sth.nhs.uk

1 The Medical School, University of Sheffield Medical School, Sheffield S10 2RX, UK

2 Department of General Surgery, Sheffield Teaching Hospitals, Sheffield, UK

3 Department of Psychology, Leeds Beckett University, Leeds, UK

4 Department of Gastroenterology, Sheffield Teaching Hospitals, Sheffield, UK
International Patient Decision Aids Standards (IPDAS) and DISCERN criteria. The readability of the source content was assessed using the Flesch-Kincaid score.

Results Of the 201 sources found, 187 were excluded, leaving 14 sources for analysis. Three sources were dedicated to $\mathrm{pCD}$, and six sources mentioned $\mathrm{pCD}$-specific outcomes. The most common surgical intervention reported was seton insertion $(n=13)$. The least common surgical intervention reported was proctectomy $(n=1)$. The mean IPDAS and DISCERN scores were $4.43 \pm 1.65$ out of 12 (range $=2-8$ ) and $2.93 \pm 0.73$ out of 5 (range $=1-5$ ), respectively. The mean reading ease was US college standard.

Conclusions We found no patient decision aids relating to surgery for $\mathrm{pCD}$. The online sources relating to surgery for pCD are few, and their quality is poor, as seen in the low IPDAS and DISCERN scores. Less than half of the sources mentioned pCD-specific outcomes, and three sources were solely dedicated to providing information on $\mathrm{pCD}$. Healthcare professionals should look to create a patient tool to assist decision-making in $\mathrm{pCD}$.

Keywords Surgery · Perianal Crohn's fistula · Internet . Information

\section{Introduction}

Crohn's disease (CD) is one of the two major forms of inflammatory bowel disease (IBD) [1, 2]. It is a chronic, relapsing-remitting disease characterised by granulomatous inflammation which can affect any part of the gastrointestinal system [3, 4].Up to $30 \%$ of patients with CD develop a perianal fistula [3,5]. Perianal Crohn's fistula (pCD) is a debilitating manifestation of CD and adversely 


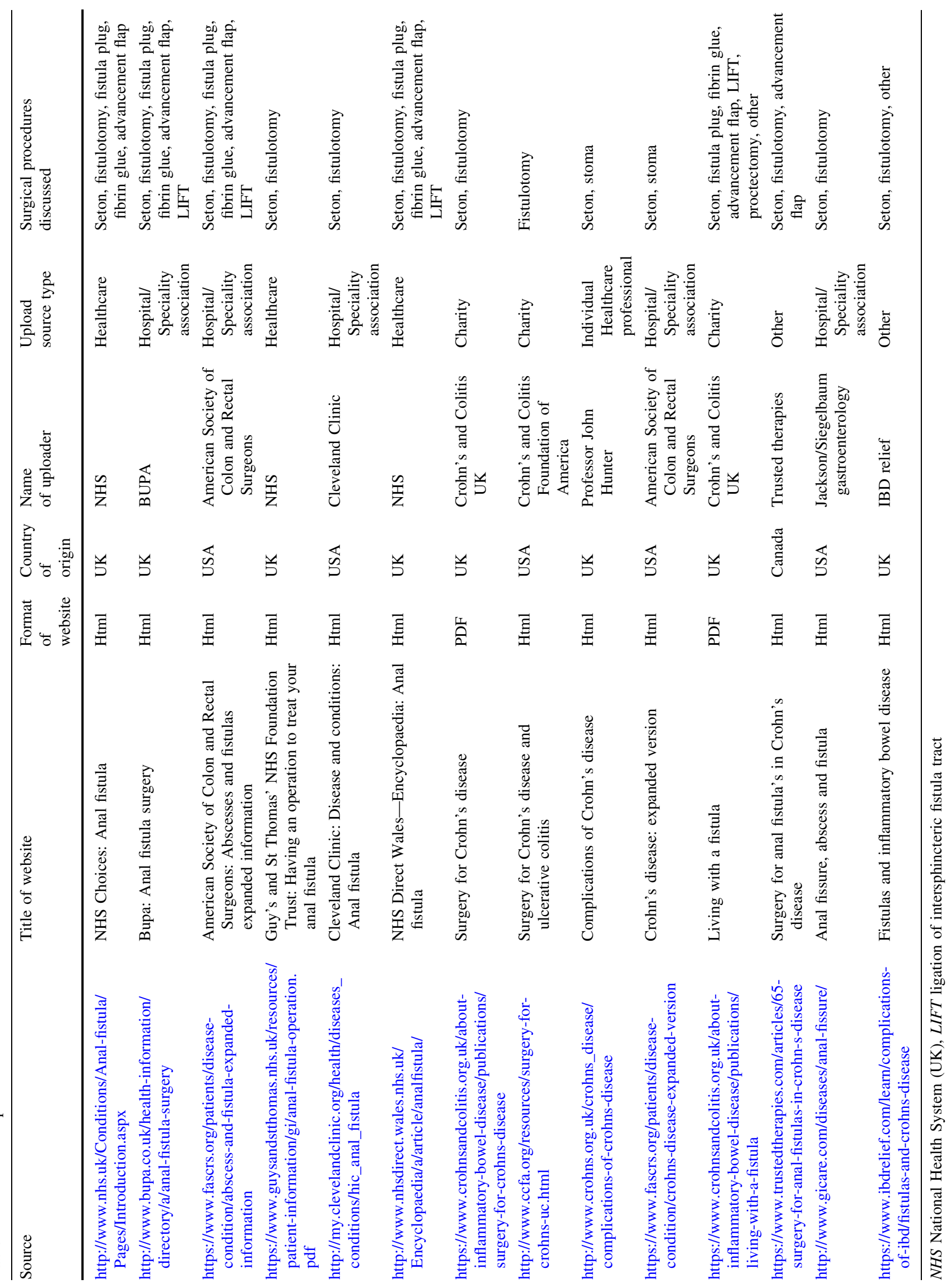


affects patient quality of life [6-8]. The management of pCD is a challenge for clinicians as there is more than one treatment option [9, 10]. The European Crohn's and Colitis Organisation (ECCO) advocates a combined medical and surgical approach to treat pCD [11]. However, surgical intervention is required in $70-85 \%$ of those affected $[12,13]$. The choice of procedure is dependent on the anatomy of fistula, surgical experience, and presence of local CD [14].

The internet has become a source of healthcare information for patients who suffer from IBD [15]. The Royal College of Surgeons of England advises clinicians to direct their patients to use the internet to inform themselves of treatment options, so as to promote shared decision-making (SDM) [16]. SDM is the concept applied when discussing preference-sensitive decisions, as may be the case with pCD. The informed patient makes a decision, with their clinician, based on their individual preferences and the values they place on the risks and benefits of each procedure [16-18]. Previous work has shown that patients feel empowered and in greater control of their disease when using the internet [17-19].

The aim of this systematic review was (1) to assess the quality of patient decision aids for pCD surgery and (2) to assess the quality of patient-focussed online health information relating to surgery for $\mathrm{pCD}$.

\section{Materials and methods}

This systematic review was registered with the PROSPERO database (CRD: 42016046689). The study was carried out in accordance with Preferred Reporting Items for Systematic Reviews and Meta-analyses (PRISMA) guidelines and followed a predefined protocol [20].

\section{Search strategy}

A search was carried out of (1) the World Wide Web using the Google Search ${ }^{\mathrm{TM}}$ engine (Mountain View, CA, USA) and (2) the Decision Aids Library Inventory (DALI). Google $^{\mathrm{TM}}$ and DALI were searched separately using a predefined search strategy comprised of seven search strings: (1) surgery for fistula, (2) surgery for anal Crohn's disease, (3) Crohn's disease surgery, (4) Crohn's disease fistula surgery, (5) stoma Crohn's disease, (6) rectal fistula in Crohn's, and (7) anal fistula surgery in Crohn's.

Google $^{\mathrm{TM}}$ was searched for sources relating to surgery for pCD. Internet users rarely go beyond the first page of search results [21]. For this reason, only websites on the first two pages of results were screened for inclusion in the study [21]. This was applied to all seven search strings. The abstracts of each website were screened against the eligibility criteria for inclusion in the 'full-text' review. This included removing duplicate sources. The hyperlinks of those abstracts eligible were retained to screen the website for inclusion in a full-text review.

Google $^{\mathrm{TM}}$ was used as it is considered one of the most accurate natural language search engines in the world [22]. A natural language search engine is able ascertain the user's intent from a search string [22]. This is different from information retrieval search engines which are unable to differentiate subtleties in the English language [22]. Other search engines were excluded from this study because Google ${ }^{\mathrm{TM}}$ yields the same results produced by other search engines when using the same search string [23].

Google $^{\mathrm{TM}}$ aims to provide the most relevant results from your searches based on your internet history, known as 'Google personalisation' [24]. The searches were carried out on library computers using the 'Incognito' mode so as to eliminate the effects of 'Google personalisation' [24].

The DALI database was searched for any decision aids on surgery for $\mathrm{pCD}$. Any decision aids for $\mathrm{pCD}$ surgery were included in the review.

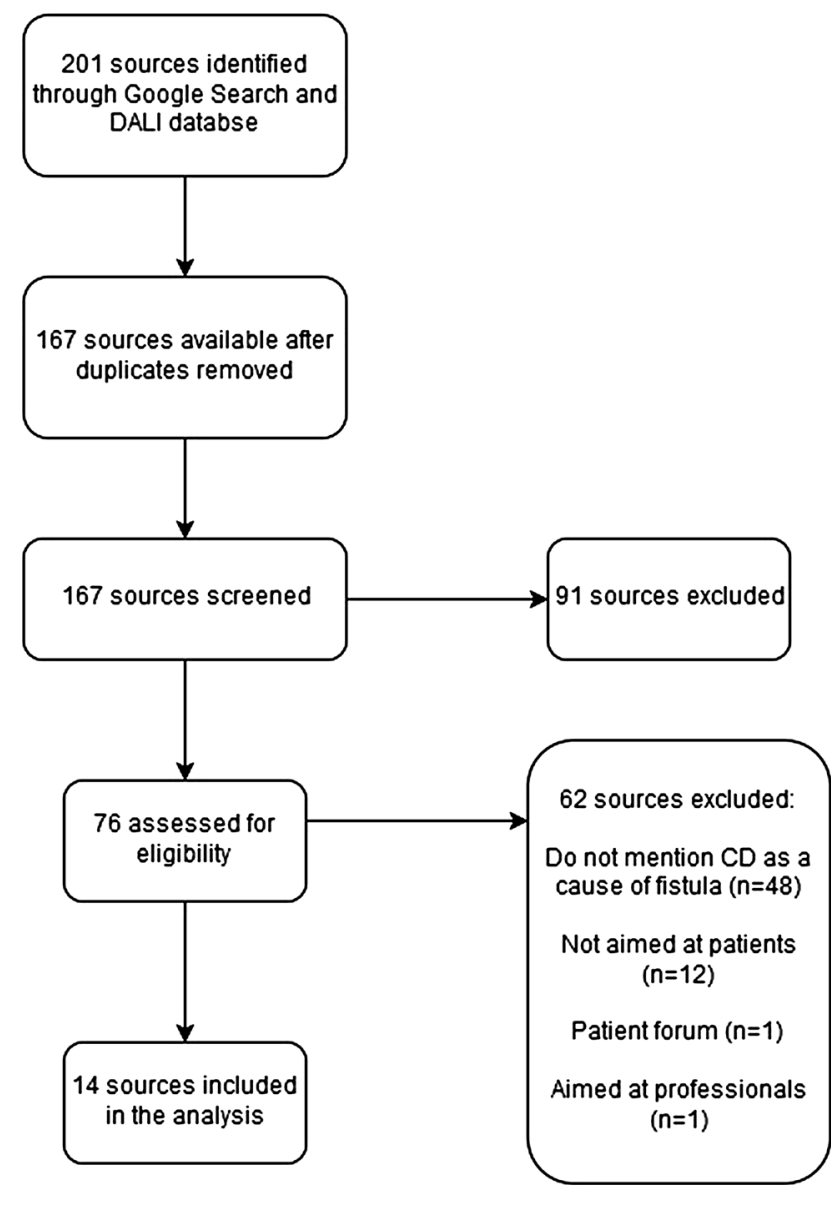

Fig. 1 PRISMA flowchart displaying the identification and exclusion process for the review 


\section{Eligibility criteria}

For inclusion in the study, the source had to discuss the surgical management of an anal fistula and report CD as a cause of fistula. The information had to be aimed at patients and not clinicians. Sources focussing solely on medical management were excluded. Non-English sources were excluded due to resource constraints. Academic literature aimed at healthcare professionals was excluded as it was thought the majority of patients would not access such material. Adverts were excluded from the study.

\section{Data collection}

The data collection was performed by two researchers (JHM and DMB). Conflicts between the two researchers were resolved by a third party (MJL).

Data were collected using an extraction form constructed on Microsoft Excel 2016 (Microsoft, Washington). Three areas of extracted data were deemed important:

1. Website descriptors URL, upload source, country of origin, format of website, and purpose of website.

2. Health condition Cause, signs and symptoms, investigations, classification, disease progression, and complications.

3. Decision-making Description of surgical options, description of interventions alternative to surgery, comparison of surgery vs no surgery, benefits and risks of surgery, and a description of the preoperative and recovery periods.

\section{Data analysis}

The ability of a source to aid patient decision-making was assessed using the DISCERN tool and IPDAS criteria.

\section{Discern: [25]}

The DISCERN tool is a validated questionnaire used to assess the quality of written health information. The tool has 15 questions and a global score. The questions are rated on a scale of 1-5 using provided criteria. A score of 1 indicates the source did not meet any of the criteria for that question. A score of 3 indicates the source partially meets the criteria for that question. A score of 5 indicates that the source met all the criteria for that question. The global score indicates the assessor's overall conclusion of the quality of the source in providing written health information and can only be given a 1,3 , or 5 .
IPDAS: [17, 26-30]

The International Patient Decision Aid Standards (IPDAS) are the result of collaboration of healthcare professionals to improve the quality of patient decision aids. Patient decision aids are tools which assist SDM by providing information and helping to elicit patient preferences. IPDAS have provided criteria for the assessment of patient decision aids (IPDASi). Three categories of criteria are reported in this instrument: qualifying, certifying, and quality criteria.

All domains of the qualifying and certifying criteria are mandatory to define a patient decision aid and avoid the risk of harmful bias. The quality criteria are desirable to strengthen a decision aid but are not necessary to define a source as a decision aid. For this reason, we excluded the quality criteria from our assessment.

\section{Readability}

The Flesch-Kincaid reading ease was calculated for each source using an online tool [31]. The reading ease is scored on a scale of 0-100 and corresponds inversely with school years, i.e. the higher the score, the lower the corresponding school year and the easier the text is to understand.

\section{Results}

\section{Website selection}

The search of Google $\mathrm{TM}^{\mathrm{TM}}$ yielded 3968,000 websites, of which 201 website abstracts were screened for inclusion in the study. Of these, 34 were duplicates and 91 were excluded. This carried 76 websites into full-text review. At this stage, 62 sources were excluded, leaving 14 sources available for analysis in the review. The process of study selection and reasons for exclusion are shown in the PRISMA flow chart (Fig. 1).

The search of DALI yielded no patient decision aids for pCD surgery.

\section{Website descriptors}

The majority of the websites were sourced from the UK $(n=8)$, with the remainder from the USA $(n=5)$ and Canada $(n=1)$ (Table 1$)$. The most common upload source was hospital/speciality association $(n=5)$. The remaining sources were uploaded by public healthcare $(n=3)$, IBD charities $(n=3)$, individual healthcare professional $(n=1)$, and two 'other' upload sources. 
Table 2 Additional areas of data extraction

\begin{tabular}{|l|l|l|l|l|l|l|l|l|l|l|l|l|l|l|}
\hline Source & 1 & 2 & 3 & 4 & 5 & 6 & 7 & 8 & 9 & 10 & 11 & 12 & 13 & 14 \\
\hline Medical management mentioned & & $/$ & $/$ & & & & & $/$ & $/$ & & & & $/$ & $/$ \\
\hline pCD specific outcome mentioned & & & $/$ & & & & & $/$ & $/$ & & $/$ & $/$ & & $/$ \\
\hline CD main focus of source & & & & & & & $/$ & $/$ & $/$ & $/$ & $/$ & $/$ & & $/$ \\
\hline pCD main focus of source & & & & & & & & & & & $/$ & $/$ & & $/$ \\
\hline
\end{tabular}

A green square indicates that a source reported an area of extracted data. A red square indicates that a source did not report an area of extracted data

\section{Health condition}

CD was the main focus of seven sources in the study, with pCD mentioned as a possible manifestation. Perianal Crohn's fistula was the focus of three sources in the study, and pCD-specific outcomes (such as fistula recurrence and incontinence.) were reported in 6 of the 14 sources. The most common surgical interventions reported were seton insertion $(n=13)$ and fistulotomy $(n=11)$. The least common interventions reported were stoma $(n=2)$, other ( $n=2$, both fistulectomy), and proctectomy $(n=1)$. Six sources mentioned medical management in addition to surgical management (Table 2).

\section{Readability}

The mean Flesch-Kincaid reading ease of the sources was 40.95 (standard deviation (SD) \pm 7.95 ). This value translates as the reader needing to have attended university to understand the text [32].

\section{Discern tool}

Overall, the quality of written health information in the sources was poor with a mean DISCERN score of 2.93 ( $\mathrm{SD} \pm 0.73$ ) out of 5 . Four sources received a global score of 1, and eight sources received a global score of 3. Only two sources received a global score of 5 , which is deemed excellent (Table 3).

The sources scored poorly on those questions associated with SDM. Only three sources fully explained the benefits of each treatment (domain 10), and only one source fully explained the risks of each treatment (domain 11) (Tables 3, 4). Two sources provided excellent information to support SDM (domain 15). No sources provided adequate referencing to the main claims made about the treatment of $\mathrm{pCD}$ (domains $4 \& 5$ ).

\section{IPDAS assessment}

Table 5 provides the results of the IPDAS assessment across the sources. A green square indicates the particular criterion was met as opposed to a red square which indicates the opposite. The number of green squares was calculated to produce a score out of 12 for each source. To be classed as a decision aid, all 12 criteria must be met [27].

The mean IPDAS score across the study sources was 4.43 ( $\mathrm{SD} \pm 1.65)$ out of 12 . None of the sources could be defined as a patient decision aid. Four sources described the positive features of each treatment, and six sources described the negative features. Half of the sources explicitly stated a choice about treatment was needed. All of the sources described at least one surgical option for the treatment of pCD.

\section{Discussion}

This study systematically reviewed patient-focussed online information discussing surgery for $\mathrm{pCD}$. All of the study sources were websites. We identified no patient decision aids relating to surgery for $\mathrm{pCD}$. Three websites were solely dedicated to providing information on $\mathrm{pCD}$. The most common surgical intervention reported was seton insertion $(n=13)$. The least common surgical intervention reported was proctectomy $(n=1)$. Specific pCD outcomes were mentioned in 6 out of the 14 sources. The average global DISCERN score for the study sources was 2.93 ( $\mathrm{SD} \pm 0.73$ ) out of 5 , rendering the quality of written health information poor. No source met the full IPDASi criteria to be defined as a patient decision aid. The average Flesch-Kincaid reading ease of the sources was 40.95 (SD \pm 7.95$)$. This translates as the reader needing to have attended university to understand the text [32]. 
Table 3 DISCERN assessment

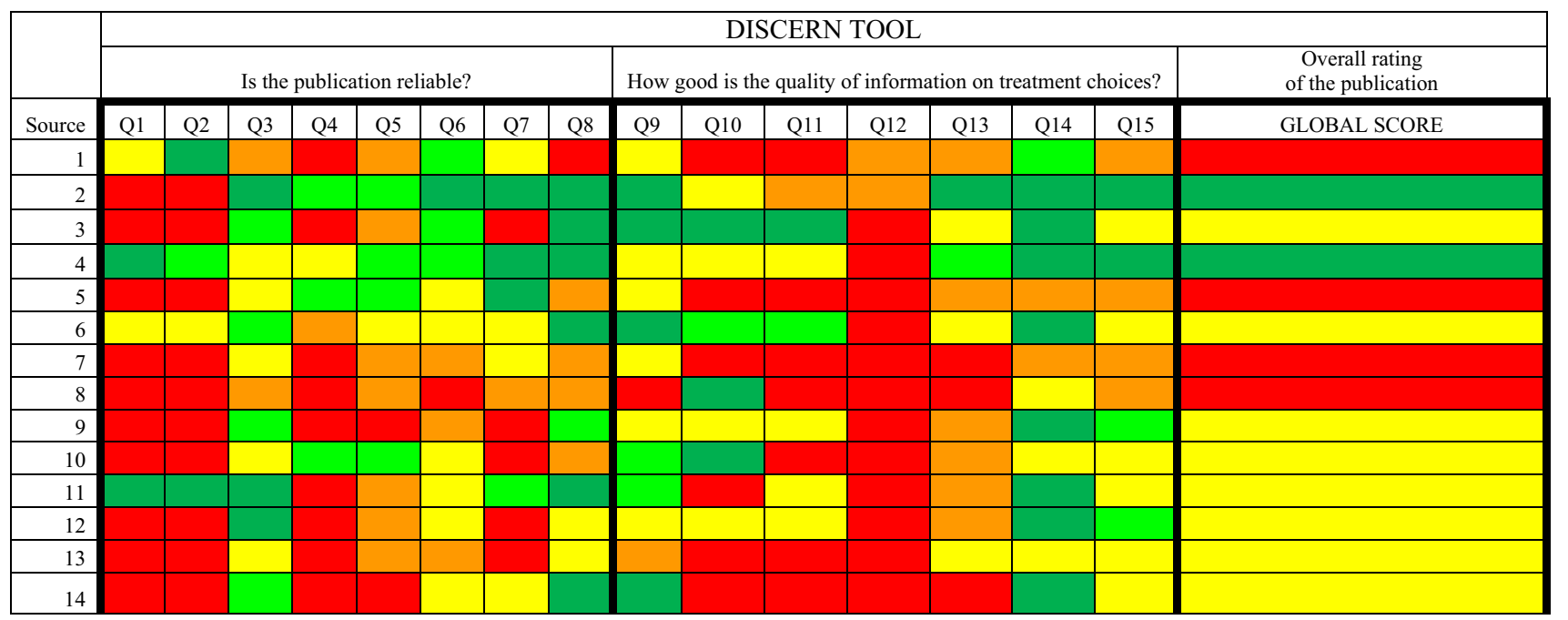

The colour of the squares indicates the DISCERN score for a particular domain for a given source: dark green $=5$, light green $=4$, yellow $=3$, orange $=2$, red $=1$

Table 4 DISCERN domains

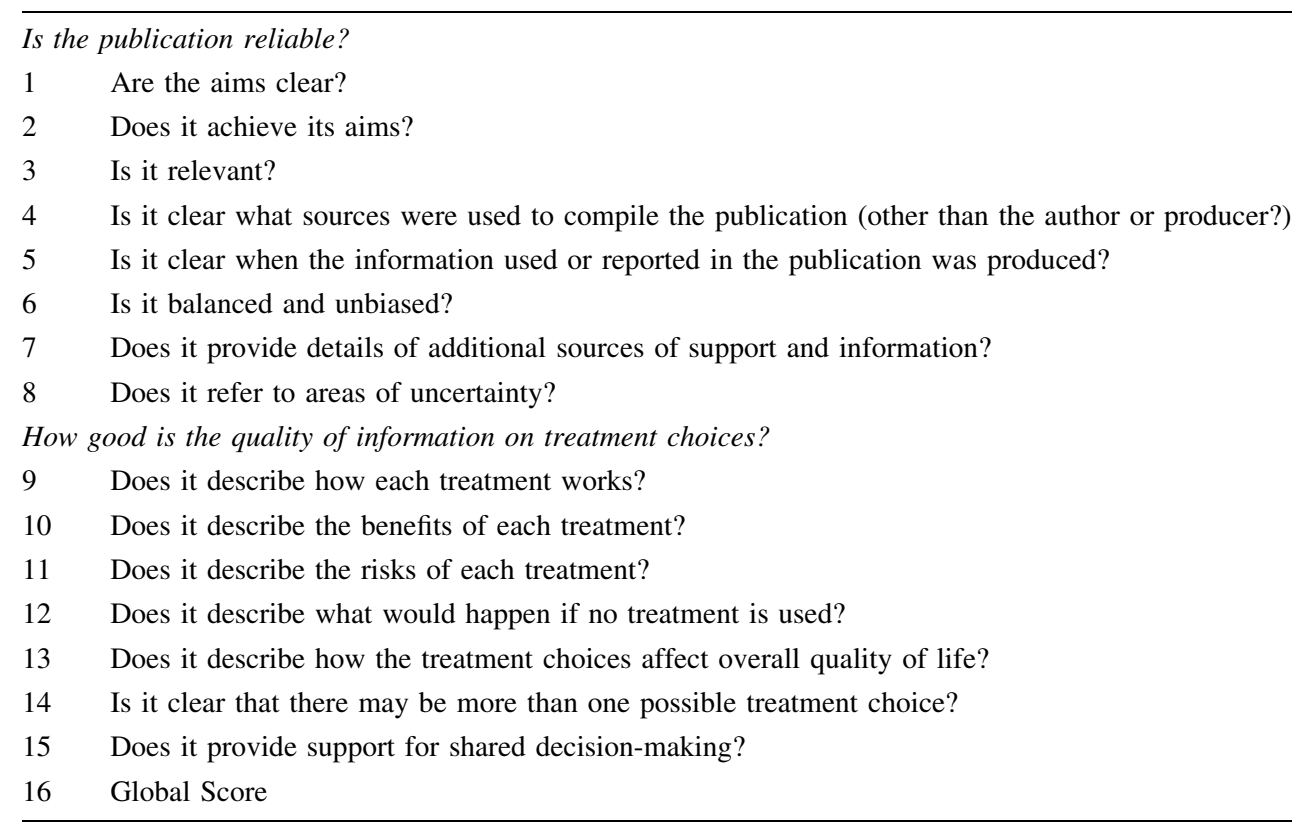

Current online health information relating to $\mathrm{pCD}$ and surgery is not a useful asset in aiding patient decisionmaking, as reflected in low DISCERN and IPDAS scores. SDM is accomplished when an informed patient makes a decision in tandem with their clinician [7, 8, 17, 28, 33]. How a patient views the risks and benefits of each option are used when making 'preference-sensitive decisions', as may be the case for pCD [7, 8, 17, 28, 33]. Despite this, 6 of the 14 sources failed to mention any benefits of the options reported. Seven of the 14 sources failed to mention any associated risks of the options reported. Previous work assessing the online health information for other conditions has produced similar findings [34, 35].

Another key aspect of SDM is the impact of the treatment option on patient quality of life. Interviews conducted separately with post-operative pCD patients have revealed 
Table 5 IPDAS assessment

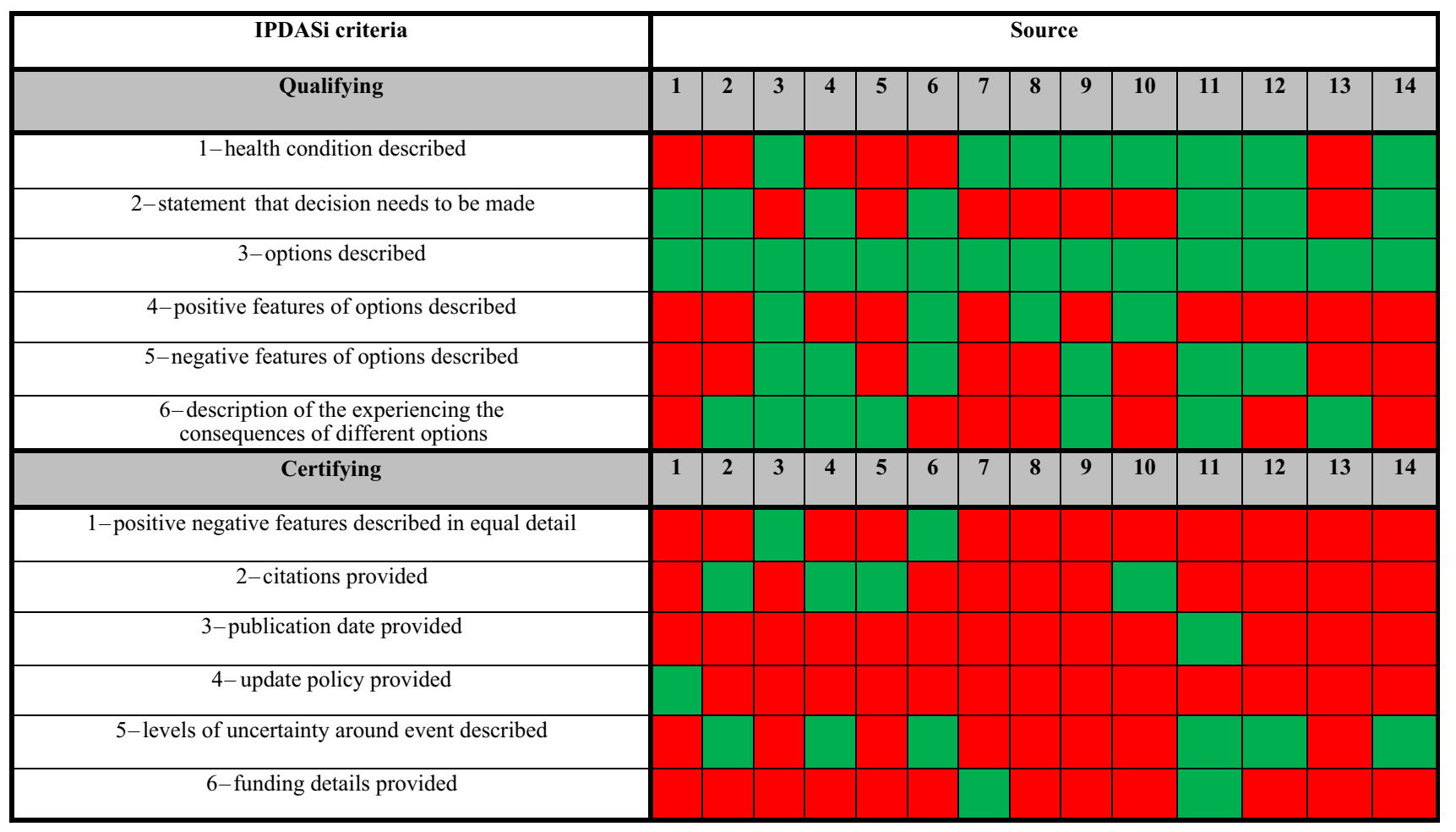

A green square indicates the source meet an IPDAS criterion A red square indicates the source did not meet an IPDAS criterion Programme used to make figure-Draw.io

they access online health information, particularly patient forums, to find out more about life after surgery. None of the sources in the study described life after surgery in much depth, perhaps due to the fact the majority of sources were uploaded by the healthcare industry. This is not a surprise as it has been shown that clinician preferences are different from those of their patients [36].

There is concern that online health information may be misleading [37]. Patient's shared experiences may describe extreme cases where information is not objective and may be irrational and biased, making it unsuitable for patient decision-making. There is concern about information overload confusing patients and clouding their judgment when making treatment choices.[38, 39] The principal concept of SDM is a joint decision made by a clinician and an informed patient and does not involve the internet $[17,18,36,40]$.

However, the SDM model encourages patients to deliberate their options away from the consultation $[17,18,41]$. This could be useful in providing patients with a balanced view between the medical and surgical management of $\mathrm{pCD}$, as previous work has shown contrasting preferences across specialities, i.e. gastroenterologists versus surgeons [40].

The readability of online health information for $\mathrm{pCD}$ is not patient friendly. There is no definitive guidance for the readability of patient-focussed health information. Public Health England advises that sources are written in clear, plain English, but also acknowledge the fact that further work is needed to assess the best format for patient-focused written health information [42]. The reading ease reported in our study does not qualify as clear, plain English and requires the reader to have attended university to understand the text [32].

Our study has a number of strengths, such as the use of $\mathrm{Google}^{\mathrm{TM}}$. Previous work has shown the majority of patients choose Google ${ }^{\mathrm{TM}}$ as a starting point when looking for online health information [21]. Google ${ }^{\mathrm{TM}}$ is one of the most accurate natural language search engines [22].

Videos were excluded from our analysis which is considered a limitation. Online health videos have become prevalent in other specialities and are used by patients [43]. There are limitations to the scoring system of the DISCERN tool. For example, many sources scored highly on 
describing more than one treatment option (domain 14). However, to score highly on this domain, the source only has to allude to the fact that other treatments may be available as opposed to describing other treatment options. For domains 10 and 11, the DISCERN tool only asks for those risks and benefits described for the procedures reported in the source. Two sources (8 and 10) both scored 'excellent' on describing the benefits of each treatment option, but only three treatment options were reported between the two sources. To make an informed choice, the patient requires the risk-benefit assessment from a number of options, which is not accounted for in the DISCERN assessment.

\section{Conclusions}

The quality of written health information discussing pCD is poor as reflected by low DISCERN and IPDAS scores. No patient decision aids for $\mathrm{pCD}$ surgery were identified in this study. It would seem counter-intuitive for clinicians not to engage with this format to help provide their patients with informative, user-friendly information to aid decisionmaking. It is advised that healthcare professionals look to develop a patient decision aid used to assist the decisionmaking in $\mathrm{pCD}$.

\section{Compliance with ethical standard}

Conflict of interest Alan Lobo is an advisory board member or received lecture fees for Takeda Pharma, Abbvie, and Vifor Pharma. The other authors declare that they have no conflict of interest.

Ethical approval This article does not contain any studies with human participants or animals performed by any of the authors.

Informed consent For this type of study formal consent is not required.

Open Access This article is distributed under the terms of the Creative Commons Attribution 4.0 International License (http://crea tivecommons.org/licenses/by/4.0/), which permits unrestricted use, distribution, and reproduction in any medium, provided you give appropriate credit to the original author(s) and the source, provide a link to the Creative Commons license, and indicate if changes were made.

\section{References}

1. Birrenbach T, Böcker U (2004) Inflammatory bowel disease and smoking. A review of epidemiology, pathophysiology, and therapeutic implications. Inflamm Bowel Dis 10:848-859

2. Mowat C, Cole A, Windsor A, Ahmad T, Arnott I, Driscoll R et al (2011) Guidelines for the management of inflammatory bowel disease in adults. Gut 60(5):571

3. Dasari BVM, McKay D, Gardiner K (2011) Laparoscopic versus Open surgery for small bowel Crohn's disease. Cochrane Database Syst Rev 1:1-29
4. Kalla R, Ventham NT, Satsangi J, Arnott I (2014) Crohn's disease. BMJ Br Med J 349:1-11

5. Taxonera C, Schwartz D, Garcia-Olmo D (2009) Emerging treatments for complex perianal fistula in Crohn's disease. World J Gastroenterol 15:4263-4272

6. Maeda Y, Ng SC, Durdey P, Burt C, Torkington J, Rao PK et al (2010) Randomized clinical trial of metronidazole ointment versus placebo in perianal Crohn's disease. $\mathrm{Br} \mathrm{J}$ Surg 97(9):1340-1347

7. Mahadev S, Young JM, Selby W, Solomon MJ (2011) Quality of life in perianal Crohn's disease: what do patients consider important? Dis Colon Rectum 54(5):579

8. Marzo M, Felice C, Pugliese D, Andrisani G, Mocci G, Armuzzi A et al (2015) Management of perianal fistulas in Crohn's disease: An up-to- date review. World J Gastroenterol 21:1394-1403

9. Gecse KB, Bemelman W, Kamm MA, Stoker J, Khanna R, Ng $\mathrm{SC}$ et al (2014) A global consensus on the classification, diagnosis and multidisciplinary treatment of perianal fistulising Crohn's disease. Gut 63(9):1381-1392

10. Molendijk I, Peeters KC, Baeten CI, Veenendaal RA, van der Meulen-de Jong AE (2014) Improving the outcome of fistulising Crohn's disease. Best Pract Res Clin Gastroenterol 28(3):505-518

11. Van Assche G, Dignass A, Reinisch W, van der Woude CJ, Sturm A, De Vos M et al (2010) The second European evidence-based Consensus on the diagnosis and management of Crohn's disease: Special situations. J Crohns Colitis 4:63-101

12. Michelassi F, Melis M, Rubin M, Hurst RD (2000) Surgical treatment of anorectal complications in Crohn's disease. Surgery 128(4):597-602

13. Schwartz DA, Loftus EV Jr, Tremaine WJ, Panaccione R, Harmsen WS, Zinsmeister AR et al (2002) The natural history of fistulizing Crohn's disease in Olmsted County. Minn Gastroenterol 122:875-880

14. Schwartz D, Pemberton J, Sandborn W (2001) Diagnosis and treatment of perianal fistulas in Crohn disease. Ann Intern Med 135:906-918

15. Cima RR, Anderson KJ, Larson DW, Dozois EJ, Hassan I, Sandborn WJ et al (2007) Internet use by patients in an inflammatory bowel disease specialty clinic. Inflamm Bowel Dis 13(10):1266-1270

16. England RCoS (2016) Consent: supported decision-making-a good practice guide https://www.rcseng.ac.uk/library-and-pub lications/college-publications/docs/consent-good-practice-guide/

17. Elwyn G, Laitner S, Coulter A, Walker E, Watson P, Thomson R (2010) Implementing shared decision making in the NHS. BMJ 341:971

18. Elwyn G, Frosch D, Thomson R, Joseph-Williams N, Lloyd A, Kinnersley P et al (2012) Shared Decision Making: a Model for Clinical Practice. J Gen Intern Med 27(10):1361-1367

19. Broom A (2005) Virtually He@ 1thy: the Impact of Internet Use on Disease Experience and the Doctor- Patient Relationship. Qual Health Res 15(3):325-345

20. Moher D, Liberati A, Tetzlaff J, Altman DG (2009) Preferred Reporting items for systematic reviews and meta- analyses: the PRISMA statement (Reprinted from Annals of Internal Medicine). Phys Ther 89(9):873-880

21. van Deursen AJ (2012) Internet skill-related problems in accessing online health information. Int J Med Inform 81:61-72

22. Nadjla H (2013) Do natural language search engines really understand what users want?; A comparative study on three natural language search engines and Google. Online Inf Rev 37(2):287-303

23. Kiran DPS, Pandya P, Bhatt K, Barad N, Shah N, Bargale S et al (2015) Evaluation of Health on the Net seal label and DISCERN as content quality indicators for patients seeking information 
about thumb sucking habit. J Pharm Bioallied Sci 7(6):S481S485

24. Google. Personalized search for everyone 2017 https://google blog.blogspot.co.uk/2009/12/personalized-search-for-everyone. html

25. Discern. Discern online 2017 http://www.discern.org.uk/index. php

26. IPDAS. Homehttp://www.ipdas.ohri.ca/

27. Joseph-Williams N, Newcombe R, Politi M, Durand M-A, Sivell S, Stacey D et al (2014) Toward Minimum Standards for Certifying Patient Decision Aids. Med Decis Making 34(6):699-710

28. Connor AM, Wennberg JE, Legare F, Llewellyn-Thomas HA, Moulton BW, Sepucha KR et al (2007) Toward the \&\#039; tipping point': decision aids and informed patient choice. Health affairs (Project Hope) 26(3):716

29. Stacey D, Legare F, Col NF, Bennett CL, Barry MJ, Eden KB, et al. 2014 Decision aids for people facing health treatment or screening decisions. Cochrane Database Syst Rev (1):Cd001431

30. O'connor AM, Graham ID, Visser A. 2005 Implementing Shared Decision Making in Diverse Health Care Systems: the Role of Patient Decision Aids. p. 247-9

31. Online-utility.org. Readability Calculator 2017 https://www. online-utility.org/english/readability_test_and_improve.jsp

32. Canterbury Uo. How to write plain English http://www.mang. canterbury.ac.nz/writing_guide/writing/flesch.shtml

33. Tozer P, Burling D, Gupta A, Phillips R, Hart AL. 2011. Review article: medical, surgical and radiological management of perianal Crohn's fistulas. Aliment Pharmacol Ther. p. 5-22

34. Goslin RA, Elhassan HA (2013) Evaluating internet health resources in ear, nose, and throat surgery. The Laryngoscope 123(7): 1626
35. Kaicker J, Debono V, Dang W, Buckley N, Thabane L. 2011. Assessment of the quality and variability of health information on chronic pain websites using the discern instrument. American Journal Of Epidemiology.173:S205-S

36. Byrne C, Solomon M, Young J, Selby W, Harrison J (2007) Patient Preferences Between Surgical and Medical Treatment in Crohn's Disease. Dis Colon Rectum 50(5):586-597

37. McCaw BA, McGlade KJ, McElnay JC (2014) Online health information - what the newspapers tell their readers: a systematic content analysis. BMC Public Health 14:1316

38. Liu C-F, Kuo K-M (2016) Does information overload prevent chronic patients from reading self-management educational materials? Int J Med Informatics 89:1-8

39. Sampson D. 2011. Managing the Information Overload. JognnJournal Of Obstetric Gynecologic And Neonatal Nursing. 40:S71-S

40. Byrne CM, Tan KK, Young JM, Selby W, Solomon MJ (2014) Patient and clinician preferences for surgical and medical treatment options in ulcerative colitis. Colorectal Dis 16(4):285-292

41. Mulley AG, Trimble C, Elwyn G. 2012. Stop the silent misdiagnosis: patients' preferences matter. BMJ British Medical Journal. 345

42. England PH. Improving health literacy to reduce health inequalities 2015https://www.gov.uk/government/uploads/sys tem/uploads/attachment_data/file/460710/4b_Health_LiteracyBriefing.pdf

43. Lee JS, Seo HS, Hong TH (2014) YouTube as a source of patient information on gallstone disease. World $\mathrm{J}$ Gastroenterol 20(14):4066-4070 